http://www.jfas.info

\title{
PROPOSED APPROACH FOR MODELLING OF MILITARY CAPABILITIES USING BASED PLANNING (CBP) FRAMEWORK
}

\author{
N. Hussein ${ }^{1, *}$ and N. M. Nor ${ }^{2}$ \\ ${ }^{1}$ Science and Technology Research Institute for Defence (STRIDE), Ministry of Defence \\ Malaysia, 43000 Kajang, Selangor, Malaysia \\ ${ }^{2}$ Faculty of Engineering, National Defence University of Malaysia, Sungai Besi Camp, 57000 \\ Kuala Lumpur, Malaysia
}

Published online: 10 September 2017

\begin{abstract}
Capability Based Planning (CBP) is a type of force planning which involved complex process adapted from strategic planning concept. CBP is premised upon transformational efforts in terms of future force planning, which focuses on joint operations. While the Malaysian Armed Forces (MAF) have implemented CBP since 2008, the nature of its implementation is not well understood. In this study, the methodology used to model, forecast and analyse the MAF future capabilities is proposed to be based on CBP process. Quantitative techniques of Operations Research (OR) approach and qualitative method of social science approach are proposed by combining both in a mixed methodological strategy by means of dynamic embedded design.
\end{abstract}

Keywords: embedded design; triangulation; portfolio analysis tool (PAT); cognitive interview (CI).

Author Correspondence, e-mail: norliza.hussein@stride.gov.my

doi: http://dx.doi.org/10.4314/jfas.v9i3s.40 


\section{INTRODUCTION}

Forecasts are useful in formulating future military capabilities. Forecasting and Planning (F\&P) in force planning is aimed to achieve specific goals and strategic objectives to meet future war fighting needs. Capability Based Planning (CBP) is a type of force planning involving complex process adapted from common strategic planning concept. CBP was introduced by the United States Department of Defense (US DoD) in 2001 to replace Cold War planning paradigm, known as Threat Based Planning [9] that following the aftermath of 9/11 terrorist attack in 2001. CBP and joint operations became part of the US-designed military transformation strategy that led many armed forces around the world scrambling to follow suit. Today, organizations and businesses use CBP as capabilities can provide a foundation for assessing and prioritizing the strategic mission and linking executive intent with operational activities [25]. CBP is also used to address increasing problems in designing business strategies [6], management of portfolios and identify business priorities as well as managing resources and time to understand the company's capabilities in relation to business goals [2]. Focusing on what an organization can do rather than how it can do it [1], CBP deals with uncertainty in organizational planning [20].

In military environment, the implementation of CBP varies between countries and there are 3 major strands as stated by [10]. The Anglo-Saxon approach gives scenarios a central role within CBP process and uses a combination of expert judgment and various operational analysis tools to derive capabilities in a number of sequential stages, while the French approach uses geopolitical, technological and operational perspectives to develop capabilities. Smaller countries who also professed to be practicing CBP, unfortunately do not have the tool suites to support detail capability analysis. CBP is aimed at providing the most cost and operational effective (COE) capabilities to meet wide range modern day challenges, offered flexibilities through various options to meet capability requirements [9]. With CBP, capability options and trade-offs as well as risk are considered earlier in planning stage i.e. at systems life cycle. In [7] describes CBP as providing a conceptual framework for; planning under uncertainty, an understanding on capability needs, assessing capability options at the level of mission, choosing among capability options in an integrative portfolio framework, to perform 
wide range scenarios from war (or conflicts), to stabilization and peace keeping operations.

CBP framework is decomposed into 3 areas which are the inputs (red), assessment (blue), modelling and analysis (green) shown in Fig. 1. The inputs comprise of the government strategies, policies and strategic guidance, defence priorities and future environments and uses wide ranging scenarios to provide the context against which to measure the level of capability as well as a basis for developing goals against which capabilities are assessed. Capability partitions or areas are established based on the ability to perform tasks or to deliver effects [29], as well as to avoid overlapping of areas.

The critical component of the study is capability modelling and analysis. To be fully effective, capability systems must be analyzed in the actual conduct of operations involving a 'walk down' of the deployment of military capabilities (in the in-service phase of capability development) in terms of tangible and intangible inputs, among others, assets and doctrines. Since CBP is output oriented, the future MAF capabilities in terms of assets are forecasted and planned. The generic CBP framework is shown in Fig. 1.

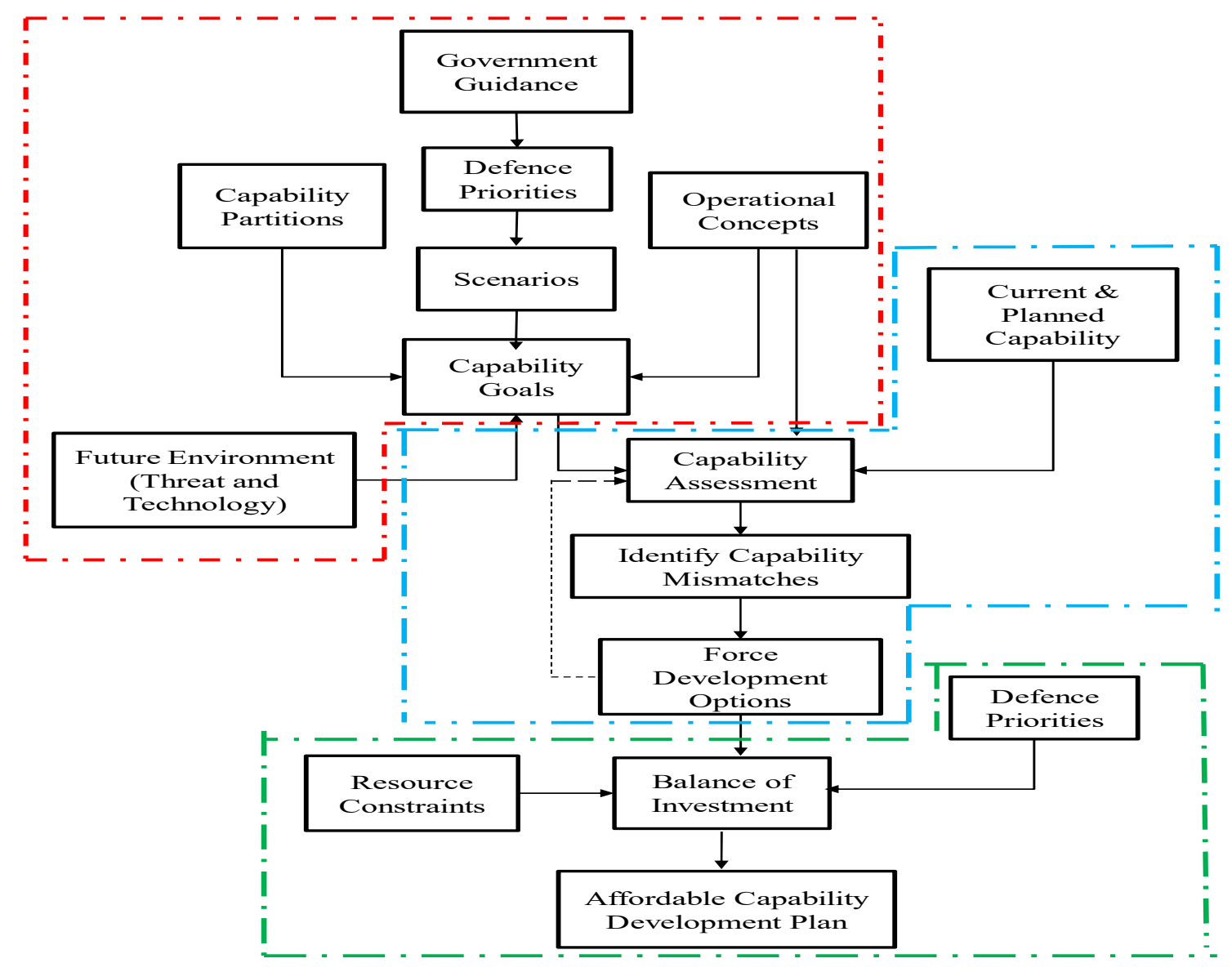

Fig.1.The generic process of CBP framework 


\section{METHODOLOGY}

Considering a comfortable worldview stance or paradigm [21] is important prior to conducting research. The epistemological stance of worldview or paradigm refers to 'a set or cluster of commonly-held beliefs or values within the research or scientific community about a field of study. The beliefs are seen as shaping or dictating how scientists and researchers should proceed in carrying out research in their field-what they should focus on, what methods to use and how the results should be interpreted' as adapted from Kuhn in 1962 and 1970 [18].

A holistic view of planning problem can be attributed to some thoughts based on System-of-Systems (SoS) as proposed by [13]. It claims the answer to capability planning would be to understand systems thinking of Defence enterprise that is structured to contribute to national power of 'influence'. This is described within the context of national interests with regards to global, regional and national environment that mediates them and the use of plausible security scenarios to articulate the implications of future influences. 'Combat power' describes national capability that is adaptable to an uncertain future which is highly complex, expensive, time consuming and may involve risks. Future planning analysis uses top-down approach in terms of appreciation of security context, bottom-up that considers future warfare concepts and the judgment assessment on the impact of technologies in shaping the concepts of future warfare. The middle-out approach looks into future military objectives through plausible scenarios within global, regional and national context and future warfare concepts.

This worldview poses a new approach to conduct research on force planning. In [19] suggest complex systems such as defence requires a multi-disciplinary approach to problem solving. Quantitative and qualitative data and analyses combined will provide a comprehensive representation of people and process intermingled together, in quest for the desired future effect or outcome, developed in long term capability plan.

Military planning has evolved over the years with the increasing roles of Operations Research (OR) analysts to solve military problems. In OR, quantitative analysis is a key element to support managerial decision making [23] that seeks to understand complex, real world problems. In [27-28] state that OR analyst has a role which interacts between both 
management and analytical processes and these can lead to effective implementation of F\&P that can go as far as determining policies. In [27] describes the effective contribution of OR analysts in strategic planning that includes, first improving the process by which decisions are made. Second, improving the methods and tools and their usage during the process and third, improving the understanding of the participants in the process. Before these can take place, the problems must be first understood, modelled and finally the suitable tools for the problems are identified [28]. This understanding is utilised to modify, predict system behaviour, produce and improve system performance [16]. He suggested that theoretical method should begin with a simplified representation, understand them and compared with actualities before further complexities can be included in.

Capability planning in the context of Malaysia requires in understanding the constituents within the system (force planning system) and their interactions in developing future capabilities and assessing transformational efforts. Qualitative issues that determine and shape the culture of the organisation are as important as the quantitative processes [17]. Capturing qualitative data in the MAF capability planning is as important as quantitative data in order to understand the implementation of CBP as well as the notion of military transformation in the Ministry of Defence (MINDEF). Forecasting that uses human judgment, however is fraught with biasness which may affect accuracy of the results.

As military problems are complex in nature, F\&P of the MAF future capability decisions must be guided by an appropriate research design. Quantitative techniques of OR approach and qualitative social science approach are proposed in the study by combining both in a mixed methodological strategy by means of dynamic embedded design. Dynamic approach was proposed where systems-thinking is focused on design process that considers and interrelatesmultiple components of research design namely, study purpose, conceptual framework, research questions, methods and validity considerations [5]. In this study, the multiple components are explained as follows and in no particular order. The thought process involves viewing the MAF capability planning in a systems approach. This approach would involve looking at capability planning in broad terms before narrowing down to determination of military capabilities to meet the first component, i.e. the study purpose. 
The purpose of study is to forecast and plan military capabilities for future needs. This type of study is concerned with the most appropriate assets and force structures that contribute towards giving the most effective capabilities required by the MAF. Therefore, it is useful to consider systems thinking or SoSE of MAF planning model before the study can progress further. SoSE approach involves framing or abstracting the complex interaction between threat, technology, policy and economics and to understand the planning process within MINDEF. A Context Diagram is developed to show the interrelationships between the components of this study.

While the implementation of CBP is transformational, the nature of its implementationis not well understood. Thus, the essence of CBP as a complex process requires a cognitive process which is aimed in prompting the subjects (respondents are known as subjects in CI) to provide information that reveals signs to the processes that took place. This may involve word recognition, language processing, attention span, memory and memory retrieval and thought provoking approach whether transformation in terms of co-evolution of concepts, processes, organisations, people and technology [4] is understood. Without having a clear view of what transformational changes may involve, the interview process may not be able to capture those essence thus may lead to issue of biasness.

CI focuses on the questionnaire rather than the entire questionnaire administration [31]. These show that the holistic view of research design that involved in answering both quantitative and qualitative questions are needed. This led to exploring the options and how the subjects view transformation on capability development. Hence, the second component which is research questions of the study do not involve testing of hypotheses as there is no attempt to test a predetermined hypothesis; rather, the aim is to explore and describe in retrospective, flexibly and in detail, the perception of capability managers in the implementation of CBP and understand the notion of transformation in the MAF environment.

In terms of conceptual framework, CBP framework is also a process where the design of this research study is based upon answering research questions, developing the relevant study methodology and methods (or techniques), conforming to dynamic approach to research design. There are many inputs CBP that is affecting how the MAF employs military 
capabilities as shown in Fig. 2.

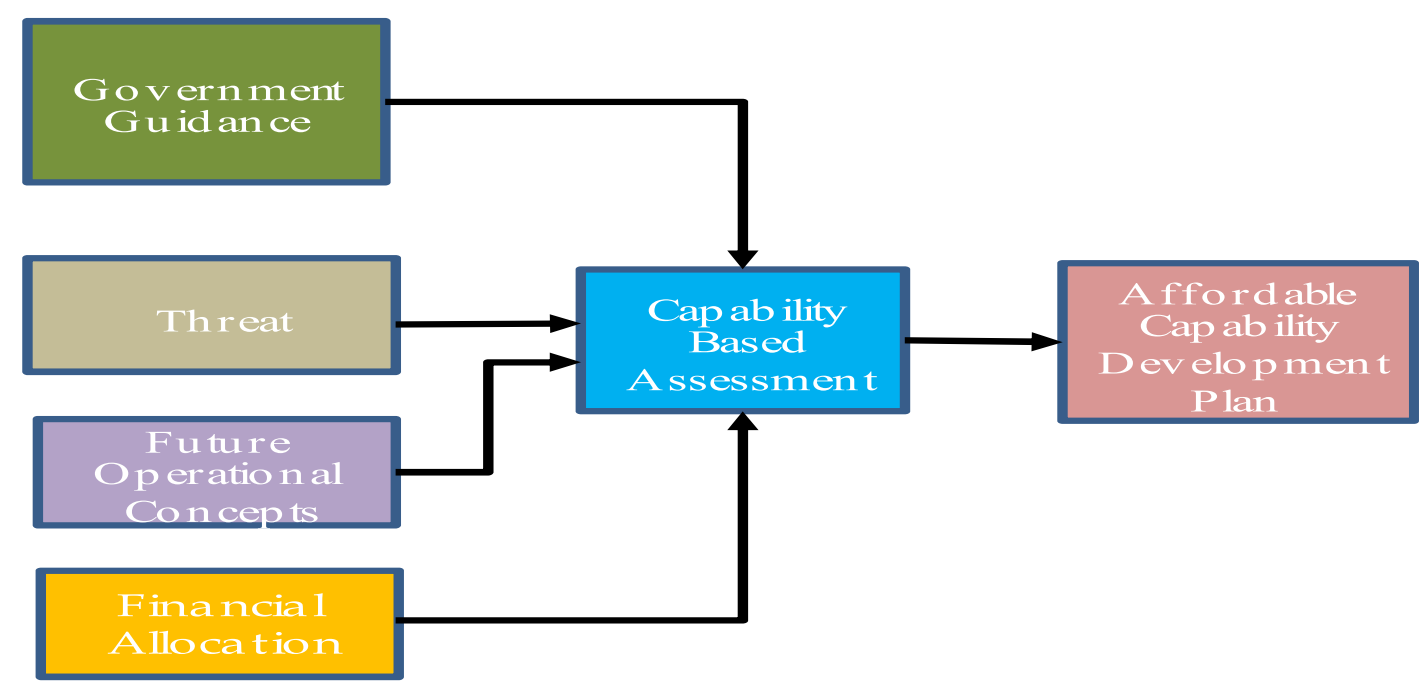

Fig.2. Conceptual framework of the MAF CBP

Inputs to future military capabilities such as operational concepts and capability partitions are reviewed from literature search, while government guidance, defence priorities and future environments are reviewed in the context of Malaysia and the MAF force planning from literatures and during interview sessions. Scenarios reflect analyses under uncertainty to provide a wide range of conditions the MAF may need to acquire to execute specified missions, while capability goals are decided based on literatures of strategic environment within the context of Malaysia.

Assessments of military capabilities are conducted based on current and planned MAF future capabilities. Force development options are developed to mitigate the capability mismatches, identified in the assessment stage. Options are defined in sufficient detail that they could be assessed by capability managers against the relevant goals [29]. OR techniques comprise of PAT and LCC are employed for assessment of operational and cost effectiveness (COE) through focus group of capability options proposed through expert judgment. Cost effectiveness (CE) uses Life Cycle Costing (LCC) tool also developed in Portfolio Analysis Tool (PAT).

This study involves answering both quantitative and qualitative questions by combining several methods together within the study known as mixed methods [5]. The methods to be used in a particular study are affected by the nature of the problem and the context of the 
problem [11]. It is proposed that the quantitative or Hard OR methods are used in SoSE, statistics, PAT and LCC while social science methods that investigate and measure 'lived experiences of the phenomenon' [5], 'as it happened or why it happened and develop from the concepts' [24] provides support to enhance the overall study. For planning under uncertainty, in [8] proposed to assessing capability options at the level of mission and choosing among capability options in an integrative portfolio framework. The proposed methodology for this research departs from the works of [8] particularly in describing the implementation of CBP and military transformation in MINDEF.

The questions were constructed based on literature and the relevance in terms of validity of the survey covers the concept it purports to measure as understood by the subjects [14]. Capability managers are experts in their fields. The study uses focus group to formulate future capabilities and the effectiveness of the options they decided during the session. Based on dynamic approach, the study applies both qualitative and quantitative strands in Capability Based Assessment (CBA) process by means of interviews (that are conducted in cognitive concurrent interview via survey questionnaire) and capability modelling during portfolio analysis by assigning probability values based on judgement by the capability managers. Portfolio Analysis Tool (PAT) allows prioritization of capability options and finally completes the study that produces an affordable future capability plan for further review by military leaders.

Dynamic embedded design is proposed due to the fact that the study is focused on the design process and the strategy for mixing occurs early at the design level, where qualitative strand is embedded as supplemental to fit the context of the quantitative design framework as intended in this study; the options and forecast of future capabilities. In the embedded design, data collection and analyses of both quantitative and qualitative data were conducted within a traditional quantitative or qualitative design [5] and findings of results are interpreted.

In terms of methods, it is a mixed method approach using a combination of techniques comprises of System-of-Systems engineering (SoSE) for system abstraction, semi structured concurrent Cognitive Interview (CI) to identify the operational circumstances and capabilities to conduct missions as well as perceptions held by capability managers (experts in the areas of 
planning, operation, training, logistics, communication and electronics, intelligence and special forces) in the general implementation of CBP and the extend of military transformation concept adopted by the MAF. The design and methods or techniques proposed in this research is shown in Fig. 3.

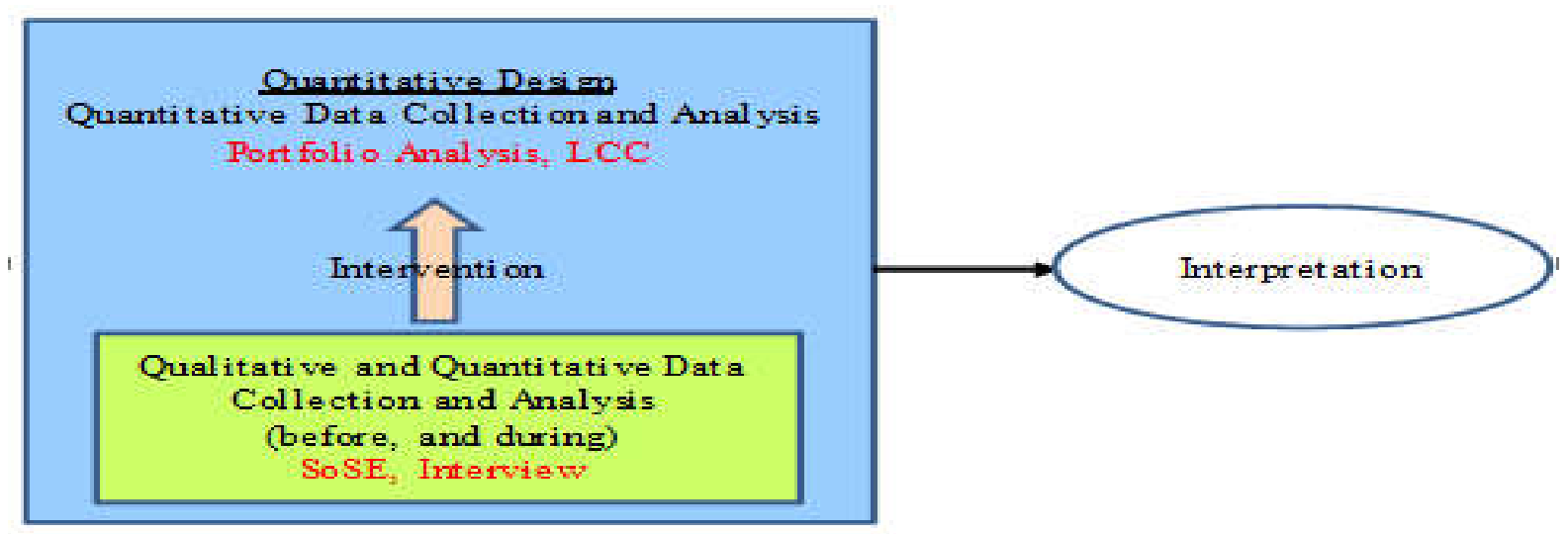

Fig.3. Proposed methodology: the dynamic embedded design

Qualitative approach involves analyzing the experience of managers in the MAF who is somewhat familiar with problem under study to interject personal experiences to data gathering and analysis process during the interviews. Extensive interaction through interviews, conversation, observation with capability managers in the MAF allows better understanding of the problem and, therefore, improving the larger design of this research. CI conducted through interviewer-administered questionnaires [22] is proposed where capability managers are asked to reflect their past experience in CBP and the notion of military transformation in the Malaysian Armed Forces (MAF). By using the past as a basis to look forward (forecast), the pace and the future capability direction as perceived by the managers.

The main disadvantage of this methodology rests with a lot input and data generated at the end of the process, and the interpretation of the results is complicated when the convergence of data may lead to inconsistencies and contradictions[15]. Therefore, scoping a complex system such as MINDEF isrequired to bring focus to the study through the development of Context Diagram.

Triangulation addresses issues of biasness with regards to judgment. Methodological triangulation defined as the use of more than two methods in studying the same phenomenon under investigation [3] involves combining both quantitative and qualitative data collection 
methods. Triangulation is appropriate based on the rationale that a single data collection method is insufficient to provide adequate and accurate results, establishes credibility that it provides confidence the results obtained are valid [26] and strengthens quantitative findings. This is a contrived study involving researcher's intervention to determine type of military missions, capability goals and the use scenarios to assess interview feedbacks. Findings from interventions during $\mathrm{CI}$ are used in focus group planning activities.

For data analysis, triangulation which is a process of combining qualitative and quantitative methods in studying the same research phenomenon was proposed in the study. The method that originates from 'triangulating' or cross examining in either one of the methods to the other in two or more ways found many applications in social sciences and behaviour research $[16,23]$. Triangulation supports interdisciplinary research rather than a strongly bounded discipline of sociology. Triangulation has several advantages in addressing issue of biasness. Triangulation of methods is aimed not only at validating but also, deepening and widening the understanding [18] in capability decisions. Corroboration between methods means that a researcher has a superior evidence of the results [3]. Also, it provides a comprehensive account (completeness) in the area of inquiry, includes diverse information from various inputs, complements one set of results with another and expands a set of results as well as eliminates missing of data if only qualitative or quantitative approach is used.

\section{RESULTS AND DISCUSSION}

Mixed methodology was not the only design evaluated for this problem. At the beginning, traditional or Hard OR that uses mathematical and quantitative techniques (also known as the positivist approach in social science) from was considered. The assets and force structure were to be assessed in terms of their effectiveness in some specific missions. Traditional or Hard OR would involve deriving measures from the dimensional parameters (both physical and structural) and measure the attributes of system behavior.For example, sensor detection probability, sensor probability of false alarm and probability of correct identification. Striving for optimization through mathematical modelling at headquarter-level planning is rather impractical to solve real life planning problems such as the MAF force planning, where 
decisions made are not fully understood. The approach taken by Dantzig in 1940's and in other previous studies illustrated the heavy use of quantitative analysis.

Statistical approach using survey questionnaire was also evaluated. A pre-test survey questionnaire was developed. However, constructing a straightforward questionnaire survey was insufficient as F\&P problem is highly complex and may lead to biasness. Therefore, the rationale of respondents' feedback is not fully understood. While, some requirements are conflicting in nature and difficult to capture using the cognitive process would eliminate the element of biasness. As such, statistical approach alone is not sufficient to capture the desirable context of this problem.

The application of Soft OR or Problem Structuring Method (PSM) was also considered. PSM are seen as complex interventions that seek action at many levels; both individually and systematically [30]. Most Soft OR methodologies however, have been borrowed or adapted from those used in other disciplines including the systems sciences and the social sciences predominantly sociology, psychology and political science. Studies on Soft OR in Defence setting are rather limited because it depends on the knowledge, experience and skills of the researcher in using both Hard and Soft approach as it is about thenature of the problem itself [12]. In the study, modelling and parts of data are provided by the subjectswho are more familiar with surveys, interview and observation subjects compared to soft OR methods. Also, lack of literatures as well as competency to conduct Soft OR approach reduces the approach to be inappropriate to conduct complex planning problem as proposed by the study and, hence was dropped.

\section{CONCLUSION}

This paper is focused on proposed methodology to conduct modelling and analysis on force planning. CBP model as shown in Fig. 1. It shows that mixed method is an appropriate approach where force planning is derived from the worldview stance based SoS thinking. Many literatures supported multidisciplinary approach to CBP to use inputs, assess current capabilities and identify in consensus capability options, assigning probability values based on judgement by the capability managers as experts for future war fighting needs are decided 
upon. Expert judgments are most likely able to close the gaps in current capabilities and make better decisions in the long run. Both quantitative and qualitative data play an important role in defining a long term needs and to capture a holistic view of planning paradigm with regards to military transformation as perceived by capability managers in the MAF. While the study may be conducted using soft (OR) PSM approach, a more practical concept abundant in social science methods is a proposed approach to model the MAF future capabilities using CBP process.

\section{REFERENCES}

[1] Aldea A, IacobM E, Hillegersberg J V, Quartel D, Franken H. Capability-based planning with ArchiMate-Linking motivation to implementation. In 17th International Conference on Enterprise Information Systems, 2015, pp. 352-359

[2] Band I, Lankhorst M. From capability-based planning to competitive advantage: Assembling your business transformation value network. 2014, https://www.slideshare.net/iverband/from-capabilitybased-planning-to-competitive-advantage -building-your-business-transformation-value-network

[3] Bryman A. Integrating quantitative and qualitative research: How is it done? Qualitative Research, 2006, 6(1):97-113

[4] Cebrowski A. K. Military transformation: A strategic approach. Washington DC: US Department of Defense, 2003

[5] Creswell J. W. Qualitative inquiry and research design: Choosing among five approaches. California: SAGE, 2007

[6] Cheng S. Translating strategy into Implementation via capability-based planning. Master thesis, Enschede:University of Twente, 2015

[7] Davis P K, Hillestad P, Long R, Dreyer D, Dues B. Reflectingwarfighter needs in air force programs: Prototype analysis.California: RAND Corporation, 2010

[8] Davis P K. Analysis to inform defense planning despite austerity. California: RAND Corporation, 2014

[9] Davis P K. Capabilities for joint analysis in the department of defense: Rethinking support 
for strategic analysis. California: RAND Corporation, 2016

[10] De Spiegeleire S. Ten trends in capability planning for defence and security. The RUSI Journal, 2011, 156(5):20-28

[11] HeyerR L. Understanding soft operations research: The methods, their application and its future in the defence setting.Canberra: Defence Science and Technology Organisation, 2004 [12] Heyer R L. Operations research and the social sciences: What are the distinctions and how can they be used in the defence environment? Canberra: Defence Science and Technology Organisation, 2004

[13] Hodge R. Defence capability development-learning from the future. In SESA/INCOSE, 1998, pp. 1-10

[14] Holden R B. Face validity. In I. B. Weiner, \& W. E. Craighead (Eds.), Thecorsiniencylopedia of psychology. New Jersey: Wiley, 2010, pp. 637-638

[15] Holtzhausen S. Triangulation as a powerful tool to strengthen the qualitative research design: The Resource-based Learning Career Preparation Programme (RBLCPP) as a case study.In Higher Education Close Up Conference 2, 2001

[16] Morse J M. Approaches to qualitative-quantitative methodological triangulation. Nursing Research, 1991, 40(2):120-123

[17] Neal D J. Do we really understand what is meant by transformational change for defence? Defence Studies,2006, 6(1):73-96

[18] Olsen W. Triangulation in social research: qualitative and quantitative method can really be mixed.InM. Holborn (Ed.), Developments in sociology, Ormskirk: Causeway Press, 2004, pp. $103-118$

[19] Orrel D, McSharry P. Systems economics: Overcoming the pitfalls of forecasting methods via a multidisciplinary approach. International Journal of Forecasting, 2009, 25(4):734-743

[20] Papazoglou A. Capability-based planning with TOGAF $\AA$ and ArchiMate ${ }^{\circledR}$. Master thesis, Enschede:University ofTwente, 2014

[21] Patton M. Q. Qualitative evaluation and research methods. California: SAGE, 1990

[22] Redline C, Smiley R, Lee M, DeMaio T. Beyond concurrent interviews: An evaluation of 
cognitive interviewing techniques for self-administered questionnaires.1998, https://www.census.gov/srd/papers/pdf/sm98-06.pdf

[23] Render B., Stair Jr R. M. Quantitative analysis for management. New Jersey: Wiley, 2000

[24] Rubin H., Rubin I. Qualitative interviewing-The art of hearing data.California: SAGE, 2005

[25] Scott J. Putting business capabilities to work. 2014, http://www.omg.org/news/member-news/OMG- Putting-Cap-To-Work.pdf

[26] Tashakkori A, Teddlie C. Past and future of mixed-methods research. In A. Tashakkori, \&C. Teddlie(Eds), Handbook of mixed method in social behaviour research. California: SAGE, 2003, pp. 671-701

[27] Tomlinson R C. Intervention-the interface between reality and thought. InG. Fandel, D. Fischer, H. C.Pfohl, K. P.Schuster, \& J. Schwarze (Eds.), DGOR-Operations Research Proceedings.Berlin: Springer, 1980, pp. 25-40

[28] Tomlinson R C, Dyson R G. Some systems aspects of strategic planning. Journal of Operational Research Society, 1983, 34(8):765-778

[29] Walker R. Towards defense capability management: A discussion paper. 2002

[30] White L. Evaluating problem-structuring methods: developing an approach to show the value and effectiveness of PSMs. Journal of the Operational Research Society, 2006, 57(7):842-855

[31] Willis G B. Cognitive interviewing: A "how to" guide. North Carolina: Research Triangle Institute, 1999

\section{How to cite this article:}

Hussein N, Nor N M. Proposed approach for modelling of military capabilities using based planning (cbp) framework. J. Fundam. Appl. Sci., 2017, 9(3S), 518-531 